\title{
Estimating the in situ state of a thickened tailings deposit
}

\author{
D Reid The University of Western Australia, Australia
}

\begin{abstract}
Estimating the in situ state that will be achieved within a thickened tailings storage facility is often challenging, as laboratory-prepared specimens are known to not necessarily reproduce the fabric and density of the tailings when they settle under full-scale high energy deposition. Samples prepared in the laboratory from non-segregating slurries often result in quite dense states, which may not occur in full-scale deposition. Some of these issues were investigated during a recent geotechnical investigation of a thickened tailings deposit. The investigation consisted of cone penetration test (CPT) probes followed by piston samples at locations directly adjacent to the probes within saturated regions near the base of the tailings. The piston samples were used to estimate in situ density by means of gravimetric water content (GWC) of the entire sample, and to provide material for preparing loose, moist tamped, reconstituted samples for measuring the critical state line (CSL) of the recovered tailings. The resulting state indicated by comparing the in situ GWCs and the CSLs agreed well with that inferred by CPT-based methods, providing additional confidence in both techniques. A reconstituted sample prepared as a slurry in the lab exhibited a denser state than that indicated from in situ GWCs, raising questions about the accuracy of laboratory-prepared slurries for investigating the density likely to be achieved in situ.
\end{abstract}

Keywords: stability, in situ state, critical state, cone penetration test

\section{Introduction}

The stability of tailings deposits is of critical concern, as indicated by several recent significant failures, each involving significant tailings discharge and flow. The ability of a tailings to undergo brittle strain softening, and hence flow, is governed by the in situ state of the tailings - in situ state being characterised through the state parameter $\Psi$ (Been \& Jefferies 1985), representing the distance between the void ratio of the material and the critical state line (CSL) at the same mean effective stress $p^{\prime}$, as summarised schematically in Figure 1.

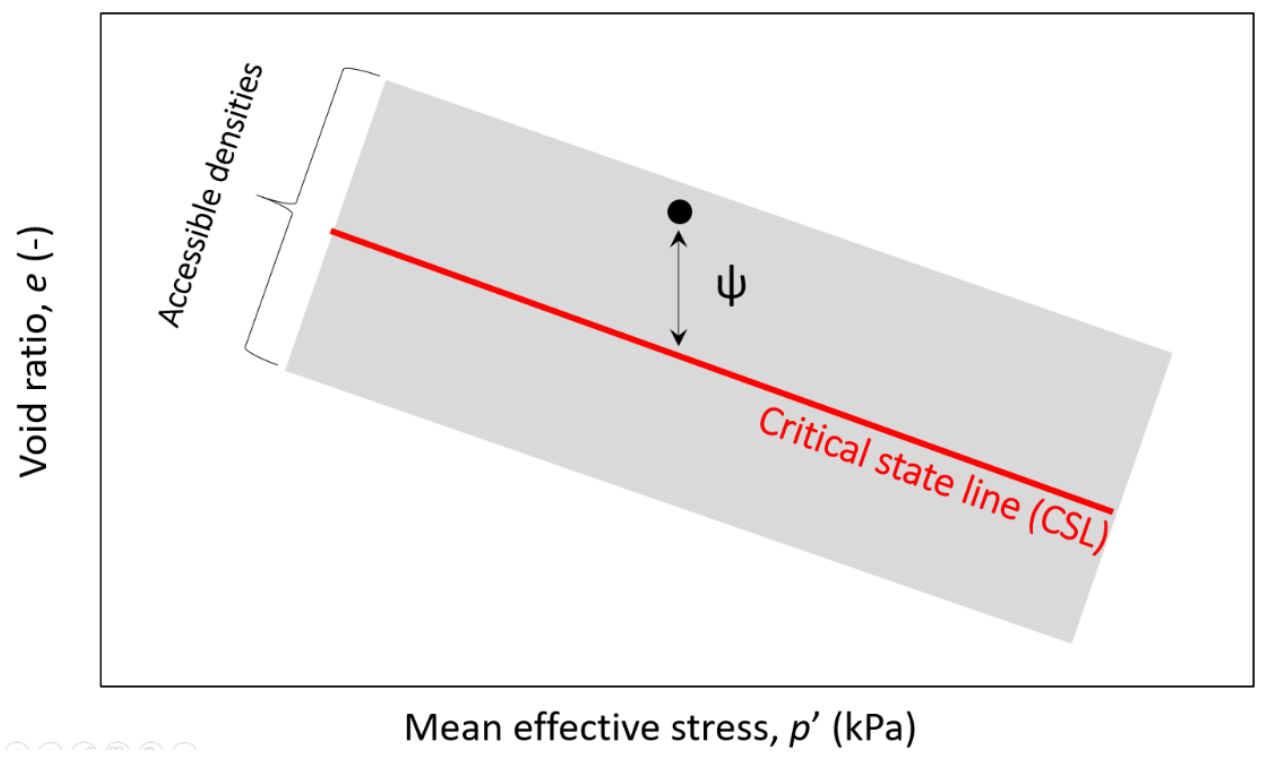

Figure 1 Critical state soil mechanics and state parameter schematic 
This paper presents the geotechnical investigation and laboratory test programs carried out to characterise a tailings deposit using the framework already outlined. The site comprised a thickened tailings stack in an arid region. The tailings are between 60 to $90 \%<75 \mu \mathrm{m}$, have Liquid Limits from 20 to 30\%, and have a plasticity index ranging from 0 to 5 . Owing to a relatively low rate of rise, and significant evaporation, much of the tailings stack was unsaturated. However, the base of the tailings in some low-lying area of the pre-tailings topography are saturated. Stability of the tailings stacks is controlled by these saturated lower tailings. This paper is focused on the characterisation of one such area.

\section{Geotechnical investigation}

The geotechnical investigation comprised cone penetration tests (CPT) with pore pressure measurement (u) at a number of locations are the tailings stack. The results were interpreted as the investigation was proceeding, to enable selection of the most critical probes, and suitable target depths for sampling. The results of the CPTu sounding that forms the focus of this paper is outlined in Figure 2, in the form of corrected tip resistance $q_{t}$, friction ratio $F_{r}$, and measured dynamic pore pressure during penetration $u_{2}$.
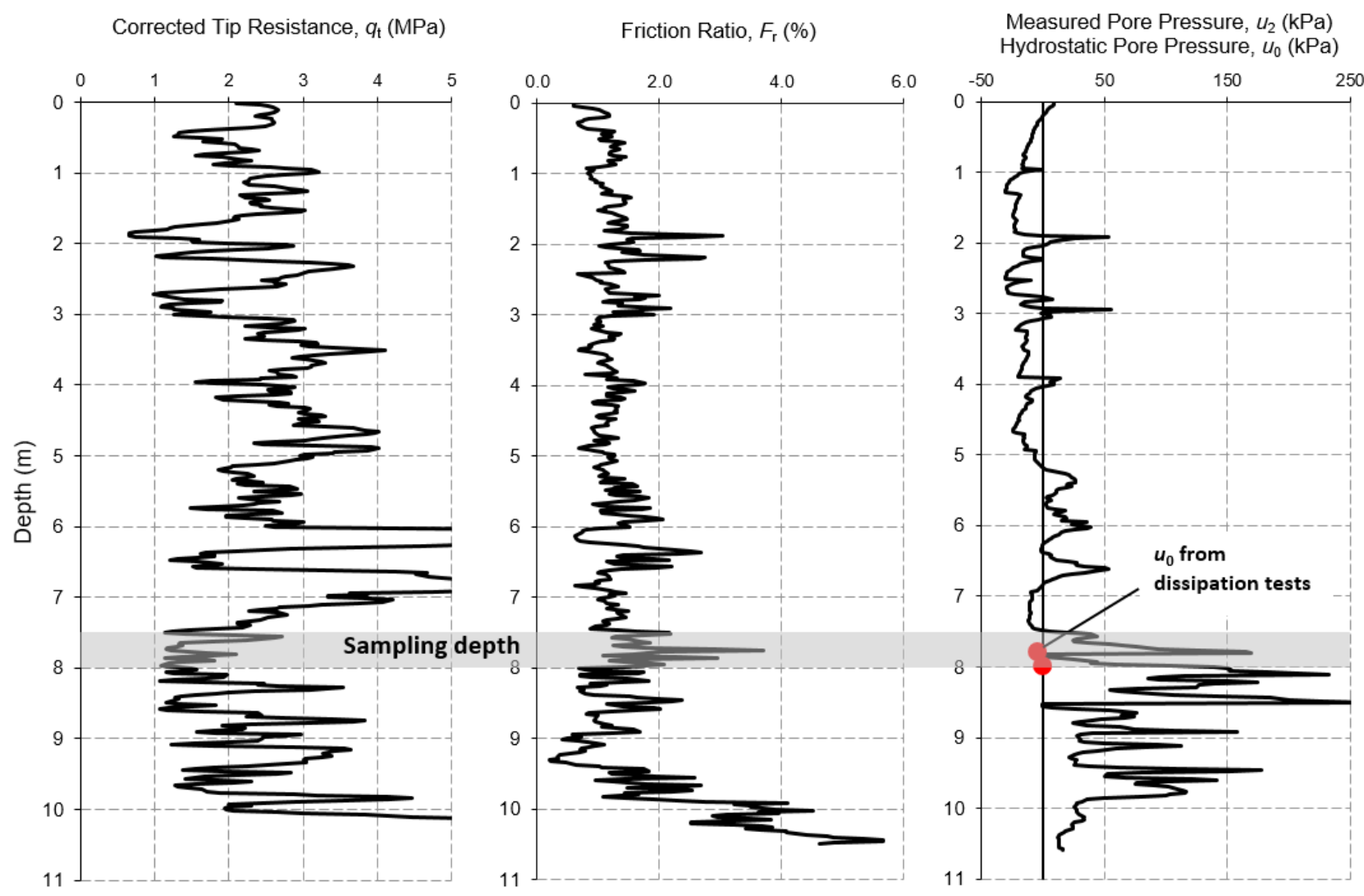

Figure 2 Summary of results for cone penetration tests (CPT) with pore pressure measurement (u)

The results indicate that the tailings are predominately unsaturated above a depth of about $7.5 \mathrm{~m}$, with primarily negative dynamic pore pressures during the sounding in this region. Between depths of 7.5 to $10 \mathrm{~m}$ the tailings appear to be saturated, below which the CPTu entered the foundation material prior to refusal.

Included in Figure 2 is the selected sample depth from 7.5 to $8.0 \mathrm{~m}$. Three tube samples were taken from the depth range, within a $2 \times 2 \mathrm{~m}$ plan area. The depth range of 7.5 to $8.0 \mathrm{~m}$ was selected as it was within the saturated stratum and had tip resistances among the lowest of any $0.5 \mathrm{~m}$ increment within the saturated tailings. This is confirmed in Figure 3, which presents the same CPTu results in the form of clean sand corrected tip resistance $Q_{\mathrm{tn}, \mathrm{cs}}$ (Robertson 2010) and $\psi$ based on the screening methods of Plewes et al. (1992) and Been and Jefferies (1992). These indicate that the saturated zone is generally contractive. The unsaturated near-surface tailings indicate dilative behaviour based on $\psi$. It should however be noted that 
where the tailings becomes saturated the CPTu-inferred $\psi$ from unsaturated tailings is unlikely to be representative (e.g. Pournaghiazar et al. 2013).

Clean sand normalised CPT penetration resistance, $Q_{\mathrm{tn}, \mathrm{cs}}$

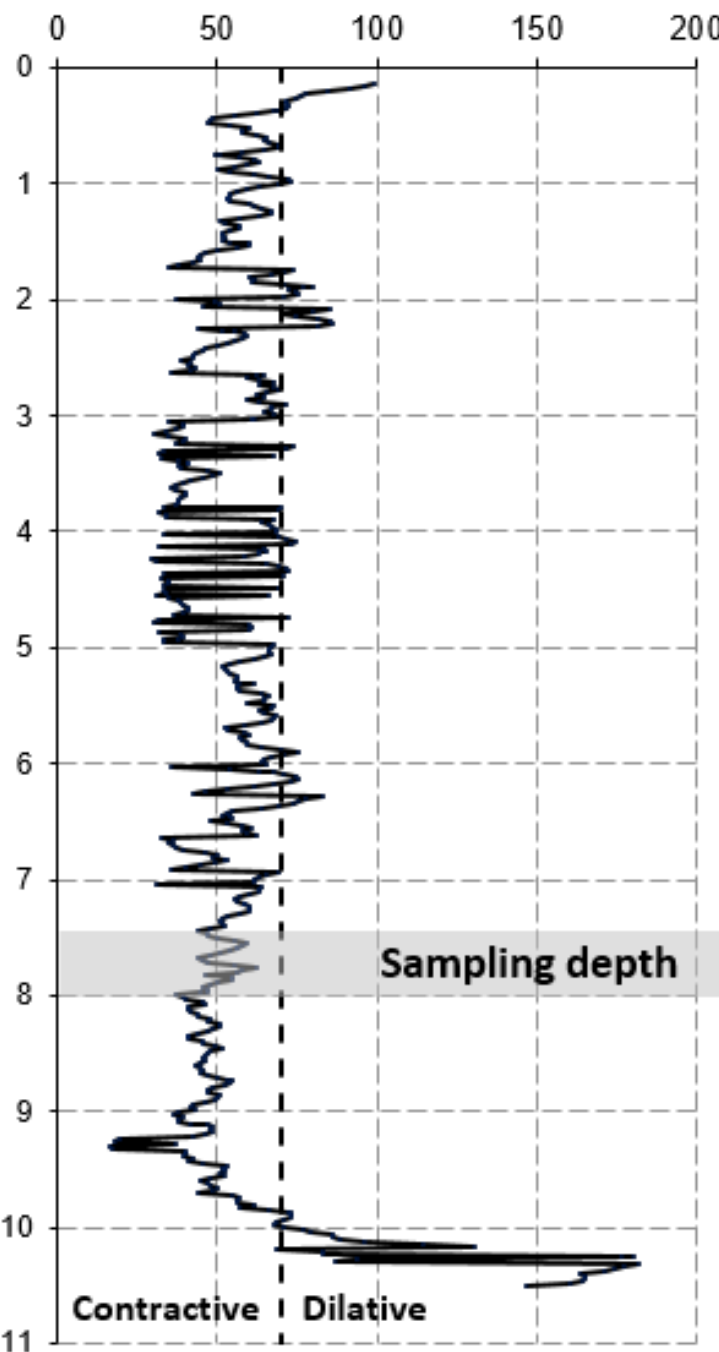

State Parameter, $\psi$

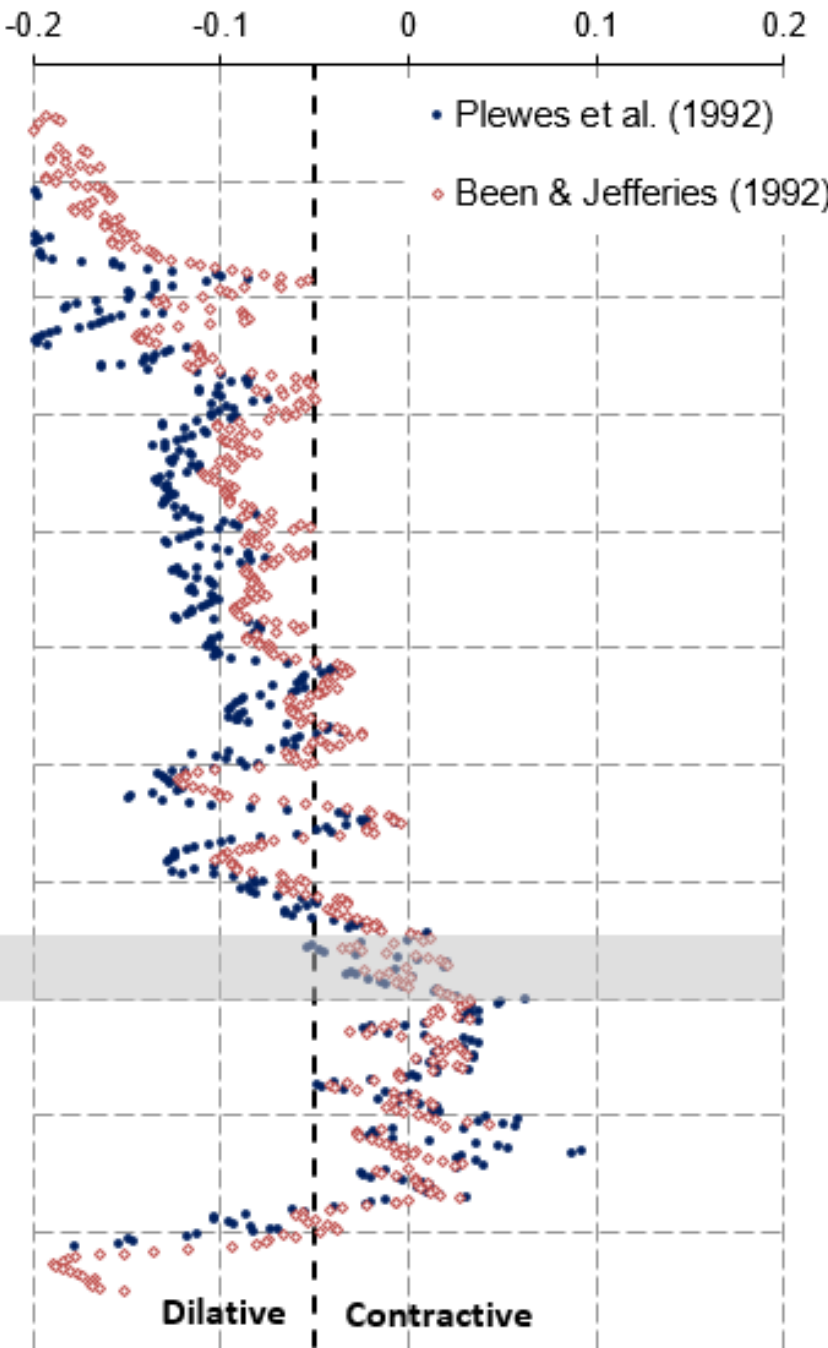

Figure 3 Contractive/dilative assessment results for cone penetration tests (CPT) with pore pressure measurement $(\mathrm{u})$

It is noted that dissipation $t_{50}$ times ranged from 5 to 45 seconds throughout the tailings, indicating partial CPTu drainage during penetration (Dejong \& Randolph 2012). Therefore, more sophisticated methods to infer $\Psi$ based on drained (Shuttle \& Jefferies 1998) and undrained (Shuttle \& Cunning 2007) penetration cannot be applied to the sounding presented here.

\section{$3 \quad$ Laboratory testing}

\subsection{Sample measurements and preparation}

As indicated previously, three tube samples of $0.5 \mathrm{~m}$ length were obtained from the target depth range of 7.5 to $8.0 \mathrm{~m}$. Owing to the sampling methods used, long road transport distance to the testing laboratory, and low plasticity of the tailings, testing samples extruded from the tubes in an 'intact' manner was not considered practical. Rather, the material from each tube was extruded in its entirety into a drying tin, and initially dried in a 'cool' $\left(\sim 50^{\circ} \mathrm{C}\right)$ oven. A subsample was then taken from this largely dry material for further drying in a 'hot' $\left(\sim 105^{\circ} \mathrm{C}\right)$ oven. This process enabled the gravimetric water content (GWC) of each tube 
sample to be obtained - without exposing the vast majority of the recovered sample to hot oven drying, which could affect the properties of low plasticity tailings. The measurement of GWC on each tube sample enables density and void ratio to be calculated only if the tailings were saturated in situ. As noted previously, the sampling depth was specifically selected within a saturated portion of the tailings, for this reason.

After the drying and GWC measurement process, the remaining material from each tube, that had only been exposed to cool oven drying, was mixed to produce a single bulk sample for reconstituted laboratory testing. This was done as a single tube usually provides insufficient material for a full suite of tests to infer the CSL. As multiple samples were taken from the same depth range at locations within $2 \mathrm{~m}$ plan area from the CPTu, it made it likely that the different samples recovered would essentially have the same properties - thus justifying 'blending' into a composite batch.

\subsection{Test methods}

The tailings bulk sample was first used to carry out three triaxial tests to infer the location of the CSL. Test methods involved use of loose, moist tamped specimens prepared by undercompaction (Ladd 1978). Two isotropically consolidated drained (CID) tests and one anisotropically consolidated undrained (CAU) test were carried out to define the CSL across a range of relevant mean effective stresses. Testing included the use of oversized, lubricated end platens to promote homogenous sample deformation and end-of-test soil freezing for more accurate void ratio measurement. These methods represent the current state of practice for the measurement of the CSL of tailings (Jefferies \& Been 2015).

In addition to the moist tamped samples, an additional sample was prepared from a thick, non-segregating slurry. This was accomplished by pouring the slurry into a membrane lined split mould, which features an 'extension' piece to enable filling the mould with an additional height of sample. This allowed the sample to be poured as a slurry, then one-dimensionally loaded using a 'hanger' system to about $25 \mathrm{kPa}$. After completion of settling and consolidation under the hanger system, the material was trimmed to the appropriate height, and a top cap placed on the specimen. A suction of $20 \mathrm{kPa}$ was then applied to the sample, which was sufficient to maintain it upright while the split moulds were removed and the triaxial cell was assembled. This sample was then consolidated under CAU conditions and sheared undrained.

\subsection{Results}

The results of the four triaxial tests are presented in Figure 4. The loose moist tamped samples were all consolidated along a relatively similar normal consolidation line (NCL), and all tend towards a single well-defined CSL. The CSL can be identified by a logarithmic expression with slope $\lambda_{\mathrm{e}}$ of 0.044 and $\mathrm{p}^{\prime}=1 \mathrm{kPa}$ intercept $\Gamma$ of 0.87 . These are reasonable values for a sandy silt tailings.

The sample prepared from a thick slurry exhibits a much lower, normally consolidated, void ratio compared to the moist tamped specimens. However, the slurry sample dilates in a manner consistent with its in situ state compared the moist tamped-inferred CSL, and the slurry sample appears to be tending towards the CSL. This different range of achievable densities from different laboratory test methods has frequently been observed in low plasticity sandy materials (Ishihara 1993; Jefferies \& Been 2000). Indeed, even different non-segregating slurry densities have been observed to result in different NCLs for some materials (Reid \& Fourie 2015).

The dilative tendency of the slurry-deposited sample is encouraging in terms of stability of the thickened tailings stack, should it be relevant to in situ behaviour. This should be compared to the contractive, strain softening of the moist tamped samples. The relevance of the dilative slurry sample however depends on the in situ states observed in the saturated portions of the tailings stack, as discussed subsequently. 


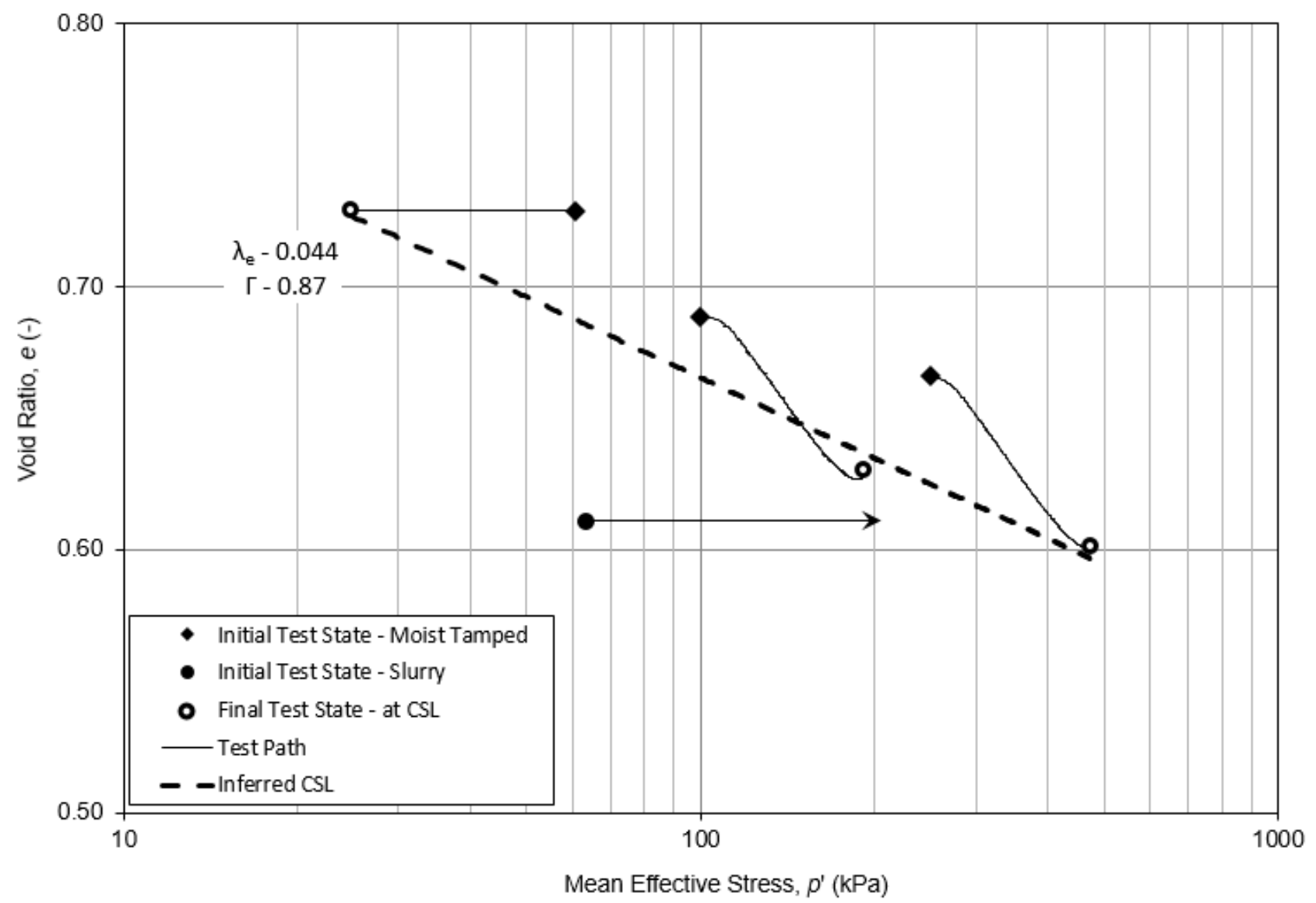

Figure 4 State diagram for the recovered sample

\section{Synthesis of results and discussion}

\subsection{Comparison of laboratory and in situ states}

Thus far, the CPTu results and laboratory testing have been presented in isolation. However, the purpose of the sampling adjacent to the CPTu probe was to enable a synthesis of the data from each, which enables refinements of the methods used to infer state and soil behaviour.

The primary synthesis is presented in Figure 5, which combined the following data using the methods outlined:

- The consolidated densities of the laboratory tests prepared using moist tamping and from a slurry.

- The CSL inferred from the moist tamped samples.

- The in situ densities measured from tube sample GWC.

- A range of void ratios from the $10^{\text {th }}$ to $90^{\text {th }}$ percentile, derived from the CPTu results based on the $\psi$ values calculated using the Plewes et al. (1992) framework, but with site specific $\lambda_{e}$ of 0.044 derived from the CSL testing. 


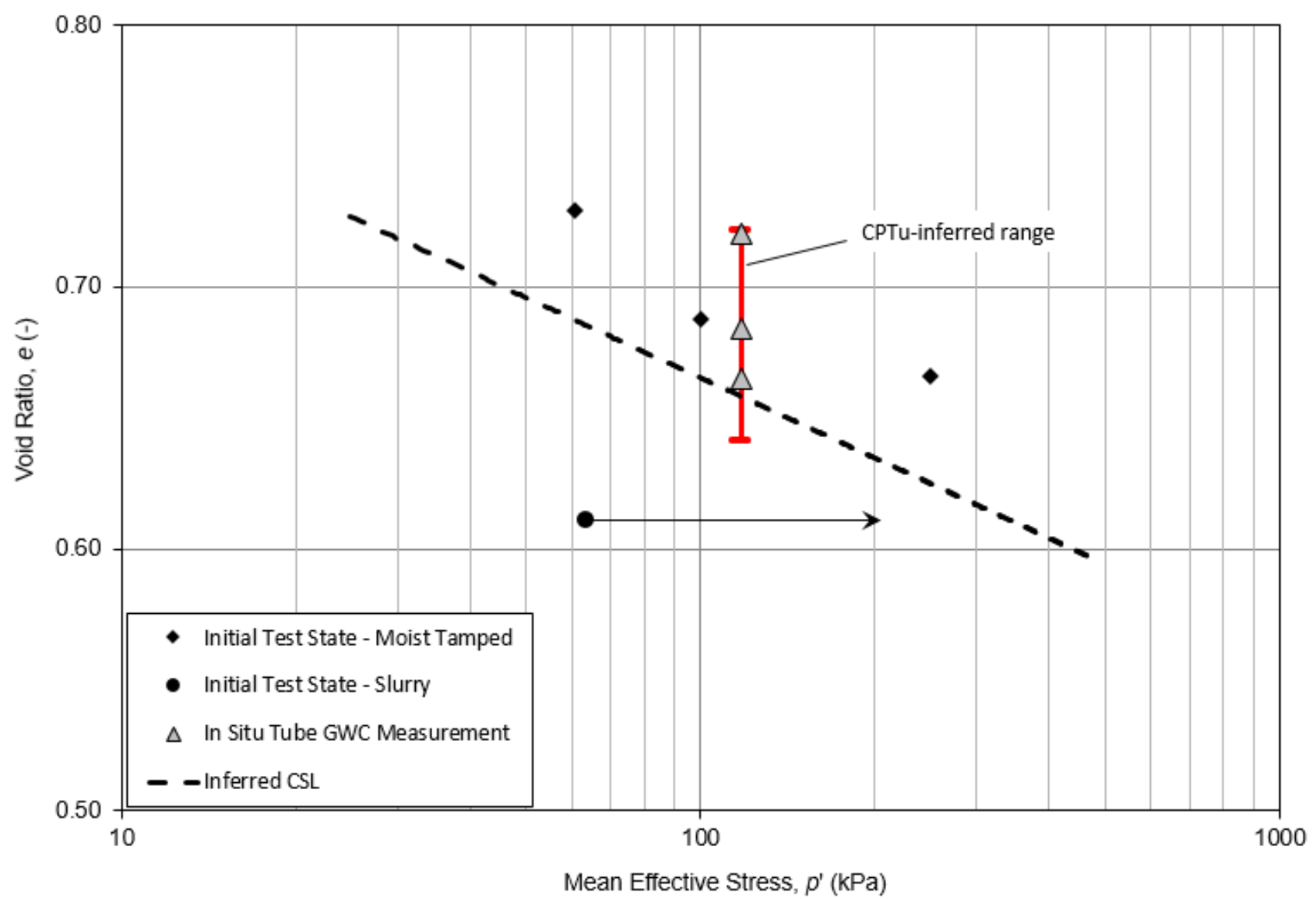

Figure 5 Laboratory and in situ state synthesis

The CPTu results span a wide range of states, from $\psi$ of about -0.02 to +0.06 . This may be a result of the layering that is inherent to most tailings deposits. Importantly, all of the void ratios measured from tube sample GWC are within the span of the CPTu-inferred results, providing increased confidence in both.

In terms of the relevance of laboratory-reconstituted samples, the moist tamped specimens appear to be along an NCL that falls within the range of states implied from both the CPTu and in situ GWC measurements. This increases confidence that the contractive strain softening behaviour suggested by moist tamped specimens is representative of what would be expected from the contractive, saturated portions of the tailings. Alternatively, the slurry-prepared sample is much denser than the range of inferred in situ $\psi$. Therefore, the dilative behaviour exhibited by the slurry sample is unlikely to be representative of in situ behaviour.

\subsection{Discussion of slurry-preparation method}

It is worth considering why the slurry sample prepared in the laboratory had a higher density than the in situ state of the tailings. In particular, as the deposit investigated herein comprised thickened non-segregating tailings, one would generally expect that a laboratory sample preparation method that simulate the field placement (i.e. slurry preparation) would yield the most representative samples. One possible reason for the lack of agreement of laboratory and in situ samples may be that the samples were recovered from what was once a topographical low point of the tailings deposition area. As such, during early stages of deposition, when thickener performance was possibly less optimised, it is conceivable that standing water was present in the low area from where the samples tested herein were recovered. As such, their deposition would be subaqueous. There is increasing evidence that silty tailings subaqueous deposited achieved looser states than those deposited subaerially on a tailings beach (Reid et al. 2018; Reid \& Jefferies 2017). Indeed, a similar comparison to the one carried out herein on a subaqueously deposited conventional tailings indicated similarly loose states that could not be replicated in the laboratory (Reid 
et al. 2018) - with detailed gradation testing indicating the loose state was not a result of segregation within the in situ specimens.

Whatever the cause of the discrepancy, it is clear that the laboratory-prepared slurry sample was much denser than in situ. Although this was only from one test in this study, it is consistent with other similar observations with subaqueously deposited silts. As such, use of the results of a reconstituted laboratory test, in isolation, to characterise in situ tailings would not be advisable. This highlights the importance of developing a synthesis of in situ state from both laboratory and CPTu-related means.

\section{Conclusion}

A geotechnical investigation and laboratory testing program were carried out on a thickened tailings storage facility. The saturated zone near the base of the tailings was the focus of the laboratory test program. Piston samples were recovered from a target depth within the saturated region in order to measure in situ density and provide material for reconstituted samples. This material was then used to identify the CSL for the tailings.

Comparison of the in situ inferred state from the CPTu and measured in situ densities shows good agreement. Further, laboratory specimens prepared using moist tamping produced states consistent with those inferred in situ. However, preparation of samples using laboratory slurry settling methods produced a sample denser than the measured in situ density. This result highlights the difficulty in directly reproducing field-scale deposition conditions in the laboratory, and the importance of developing a synthesis of in situ state based on both laboratory and CPTu-based methods.

\section{References}

Been, K \& Jefferies, MG 1985, 'A state parameter for sands', Géotechnique, vol. 35, no. 2, pp. 99-112.

Been, K \& Jefferies, MG 1992, 'Towards systematic CPT interpretation', Predictive Soil Mechanics: Proceedings of the Wroth Memorial Symposium, Telford, London, pp. 121-134.

Dejong, JT \& Randolph, M 2012, 'Influence of partial consolidation during cone penetration on estimated soil behavior type and pore pressure dissipation measurements', Journal of Geotechnical and Geoenvironmental Engineering, vol. 138, no. 7, pp. 777-788.

Ishihara, K 1993, 'Liquefaction and flow failure during earthquakes', Géotechnique, vol. 43, no. 3, pp. 351-451.

Jefferies, M \& Been, K 2000, 'Implications for critical state theory from isotropic compression of sand', Géotechnique, vol. 50, no. 4, pp. 419-429.

Jefferies, MG \& Been, K 2015, Soil Liquefaction: A Critical State Approach, CRC Press, Boca Raton.

Ladd, R 1978, 'Preparing test specimens using undercompaction', Geotechnical Testing Journal, vol. 1, no. 1, pp. 16-23.

Plewes, HD, Davies, MP \& Jefferies, MG 1992, 'CPT based screening procedure for evaluation liquefaction susceptibility', Proceedings of the 45th Canadian Geotechnical Conference, Canadian Geotechnical Society, Richmond, pp. 41-49.

Pournaghiazar, M, Russell, AR \& Khalili, N 2013, 'The cone penetration test in unsaturated sands', Géotechnique, vol. 63, no. 14, pp. 1209-1220.

Reid, D, Fanni, R, Koh, K \& Orea, I 2018, 'Characterisation of a subaqueously-deposited silt iron ore tailings', Géotechnique Letters, vol. 8, no. 4, pp. 1-24.

Reid, D \& Fourie, AB 2015, 'The influence of slurry density on in situ density', in RJ Jewell \& AB Fourie (eds), Proceedings of the 18th International Seminar on Paste and Thickened Tailings, Australian Centre for Geomechanics, Perth, pp. 95-106.

Reid, D \& Jefferies, M 2017, 'State parameter as a geological principle in tailings', in G Ward Wilson, DC Sego and NA Beier (eds), Proceedings of Tailings and Mine Waste 2017, University of Alberta Geotechnical Center, Edmonton, pp. 305-314.

Robertson, PK 2010, 'Evaluation of flow liquefaction and liquefied strength using the cone penetration test', Journal of Geotechnical and Geoenvironmental Engineering, vol. 136, no. 6, pp. 842-853.

Shuttle, D \& Jefferies, MG 1998, 'Dimensionless and unbiased CPT interpretation in sand', International Journal for Numerical and Analytical Methods in Geomechanics, vol. 22, no. 5, pp. 351-391.

Shuttle, DA \& Cunning, J 2007, 'Liquefaction potential of silts from CPTu', Canadian Geotechnical Journal, vol. 44, no. 1, pp. 1-19. 
